REVISTA DO CENTRO DE CIÊNCIAS DA EDUCAÇÃO

Volume 39, n. 3 - p. 01 - 17, jul/set. 2021 - Florianópolis

\section{Carla Aragão}

Universidade Federal da Bahia, UFBA

E-mail: aragao.carla@gmail.com

(iD) https://orcid.org/0000-0001-6619-8441

\section{Karla Schuch Brunet}

Universidade Federal da Bahia, UFBA

E-mail:karlab@ufba.br

(iD https://orcid.org/0000-0002-0908-2546

Nelson De Luca Pretto

Universidade Federal da Bahia, UFBA

E-mail: nelson@pretto.pro.br

(iD) https://orcid.org/0000-0001-8152-8963

Recebido em: 27/04/2020

Aprovado em: 09/03/2021

\section{Hackear a educação por dentro}

\author{
Carla Aragão \\ Karla Schuch Brunet \\ Nelson De Luca Pretto
}

\section{Resumo}

$\mathrm{O}$ artigo analisa as características do contemporâneo a partir do surgimento da cultura digital, em função do intenso desenvolvimento científico e tecnológico, com ênfase nas chamadas tecnologias digitais de informação e comunicação. Partindo dessa conceituação, refletimos sobre a importância da escola e, mais especificamente, sobre as possibilidades de operar profundas transformações por dentro da própria escola. Para tal, a inspiração de nossas pesquisas está nos movimentos hackers, em sua ética, cultura e pedagogia. Os hackers têm participação ativa no seu grupo social, com intensa produção de conhecimentos, fazendo-os circular para que possam ser apropriados e aperfeiçoados por todos. Ancorados em estratégias de colaboração e compartilhamento, os processos de produção desses novos aparatos buscam responder aos diferentes desafios que emergem do cotidiano. $\mathrm{O}$ artigo busca compreender quais as potencialidades dessa perspectiva para a educação, admitindo-as também como alternativas para intervenções desde dentro do sistema, naquilo que estamos denominando de construção de uma escola com um jeito hacker de ser. Concluímos desenvolvendo a ideia de que precisamos de uma escola que considere a perspectiva ativista de empoderamento, autoria e produção colaborativa como base para o fortalecimento da educação pública e democrática, fundamentada num ecossistema pedagógico de aprendizagem, comunicação e produção permanente de culturas e conhecimentos. $\mathrm{O}$ título faz referência à urgência de encontrar formas de criar cavalos de troia que desestabilizem o sistema e tomem de assalto a escola a partir de uma proposta de (re)construção colaborativa, criativa, emancipatória e democrática..

Palavras-chave: Tecnologia educacional. Educação pública. Ética e Cultura hacker. Cultura digital. 


\section{Abstract}

\section{Keywords:}

Educational

Technology. Public

School. Hacker

Ethics and Culture.

Digital Culture

\section{Hacking education from inside}

This article analyzes the characteristics of the contemporary from the emergence of digital culture, due to the current scientific and technological development, with emphasis on the ICT. Based on the conceptualization of this rapidly changing field, the article seeks to reflect on the importance of the school, and, more specifically, on the possibilities of making changes within the school itself. To this end, the inspiration of our research is in the hacker movements, their ethics, culture, and, mainly, their pedagogies. Hackers actively participate in their social group, with an intense production of knowledge, making them circulate immediately to be appropriated and perfected by everyone. Anchored in collaboration and sharing strategies, the production processes seek to respond to the different challenges that emerge from everyday life. This article moves towards understanding the potential of this perspective for education, also admitting them as viable alternatives for interventions from within the educational system, in what we call the construction of a school with a hacker way. We conclude by developing the idea that we need a school that considers the activist perspective of empowerment, authorship, and collaborative production as the basis for strengthening the public and democratic educational system that is based on a pedagogical ecosystem of learning, communication, and permanent production of cultures and knowledge. The title of this article refers to the urgency for finding ways to create trojan horses that destabilize the system and take the school environment by storm, from a construction proposal collaborative, collective, emancipatory, democratic, and creative.

\section{Resumen}

\section{Palabras clave:}

Tecnología

Educacional.

Escuela Pública.

Ética y Cultura

Hacker. Cultura

Digital.

\section{Hackear la educación desde dentro}

El artículo analiza las características de lo contemporáneo a partir del surgimiento de la cultura digital, debido al desarrollo científico e tecnológico actual, con énfasis en las TIC. Basado en la conceptualización de este campo el artículo busca reflexionar sobre la importancia de la escuela y sobre las posibilidades de realizar cambios profundos desde dentro de la escuela. Con este fin, la inspiración central de nuestra investigación está en los movimientos de hackers, su ética, cultura y, principalmente, pedagogías. Los hackers tienen una participación activa en su grupo social, con producción de conocimiento, haciéndolos circular para que puedan ser apropiados y perfeccionados por todos. Anclados en estrategias de colaboración, los procesos de producción de conocimientos buscan responder a los diferentes desafíos que surgen en el cotidiano. El artículo avanza hacia la comprensión del potencial de esta perspectiva para la educación, con intervenciones desde dentro del sistema para construir una escuela con una forma de ser hacker. Concluimos, desarrollando la idea de que necesitamos una escuela que considere la perspectiva activista del empoderamiento, la autoría y la producción colaborativa para fortalecer el sistema educativo público y democrático, que, a su vez, se basa en un ecosistema pedagógico de aprendizaje, comunicación y producción permanente de culturas y conocimiento. El título hace referencia a la urgencia de encontrar formas de crear caballos de troya que desestabilicen el sistema y tomen la escuela de asalto desde una propuesta de construcción, reiteramos, colaborativa, colectiva, emancipadora, democrática y creativa. 


\section{Introdução}

Vivemos um momento de inflexão na sociedade contemporânea. As tecnologias digitais de informação e comunicação, anunciadas como possibilidades de emancipação, entraram em xeque por conta dos movimentos oligopolistas das grandes plataformas digitais da internet. Cada vez mais envolvidos em escândalos de roubo de dados e sonegações fiscais, esses grupos comprovam que a rede distribuída não é necessariamente democrática, na medida em que pode ser também espaço de controle e vigilância, uma espécie de versão digital do panóptico idealizado pelo filósofo e jurista inglês Jeremy Bentham em 1785. O físico e cientista da computação Tim Berners-Lee, que há 30 anos submeteu a proposta original sobre como deveria ser a World Wide Web, com seus protocolos e estruturas, também está convencido de que há razões sérias para nos preocuparmos. Em artigo publicado no jornal inglês The Guardian, Berners-Lee (2017) aponta a gravidade da grande exploração comercial da rede e um possível efeito de arrefecimento na liberdade de expressão.

O fato é que o uso intensivo dessas tecnologias tem provocado uma enorme desordem mundial, com movimentos políticos que oscilam entre uma intensa utilização das redes sociais para a mobilização em direção às transformações democráticas (MALINI; AUTOUN, 2013; CASTELLS, 2013) e o uso manipulado dessas mesmas redes em busca da manutenção ou do retorno de políticas conservadoras (SAFATLE, 2018). Esse cenário vem se delineando desde o final da década de 1990 e o início do século XXI, período em que as especulações acerca das possibilidades e dos limites da internet para fins políticos tiveram visibilidade, com uma série de eventos que movimentaram os debates sobre a participação política online em todo o mundo; o papel da internet em protestos, mobilizações socais e campanhas políticas online bem-sucedidas, como as de Howard Dean, em 2004, e Barack Obama, em 2008, nos Estados Unidos; a Primavera Árabe; os protestos no Irã em 2009 (GOMES, 2018); entre outros.

Não há, nessa perspectiva, uma concepção ingênua de que mais recursos tecnológicos digitais vão resolver as questões acerca da participação ou da deliberação política, mas se sabe que eles podem, potencialmente, contribuir para o aprofundamento de direitos e liberdades nesse campo. Como observado nas eleições presidenciais brasileiras de 2018, as fake news, que deram origem à Comissão Parlamentar de Inquérito (CPI) das Fake News, atualmente em curso no Congresso Nacional, transformaram-se em estratégia de marketing político, ao passo que a aplicação de tecnologias baseadas em big datas e inteligência artificial se tornou determinante em campanhas, amparando análises e segmentações dos eleitores, bem como permitindo o alinhamento dos discursos dos candidatos com os perfis desses decisores. A Organização não Governamental (ONG) SaferNet fez um levantamento no segundo turno da eleição presidencial de 2018, divulgado pela BBC Brasil (MESQUITA, 2018), em que revelou que as denúncias de xenofobia na internet aumentaram 2.369,5\% em relação ao pleito de 2014. As denúncias de apologia e incitação a crimes contra a 
vida cresceram 630,52\%; as de neonazismo, 548,4\%; as de homofobia, 350,2\%; as de racismo, 218,2\%; e as de intolerância religiosa, 145,13\%.

Complementarmente, constatamos uma erosão do Estado de Direito em boa parte do mundo, com inúmeros países vivendo verdadeiros "estados de exceção" (AGAMBEM, 2003). A concentração de riquezas em diversos países assume proporções absurdas, promovendo desigualdades também estarrecedoras. De acordo com o Pesquisa Nacional por Amostra de Domicílios Contínua (PNAD Contínua) - Rendimento de Todas as Fontes 2019, a renda do 1\% mais rico da população brasileira, que recebia R $\$ 28.659,00$ por mês, correspondia a 33,7 vezes o rendimento da metade da população mais pobre do Brasil, que ganhava $\mathrm{R} \$ 850,00$ mensalmente (PAMPLONA, 2020). Segundo outro relatório, desta vez do banco Suíço UBS e da consultoria PWC, durante a atual pandemia, os bilionários ligados ao setor de tecnologias viram suas riquezas crescerem 42,5\% de 2018 a julho de 2020 (BILIONÁRIOS..., 2020). A revista Forbes mantém uma lista em tempo real indicando as maiores fortunas do mundo e seus donos. Na atual lista (FORBES, 2021), entre os dez maiores bilionários, o líder é Jeff Bezos, fundador da Amazon (US\$ 189,3 bilhões), seguido de Elon Musk (Tesla e Space X, U\$ 182,2 bilhões). Entre esses dez maiores bilionários, também encontramos outros nomes ligados às tecnologias de informação e comunicação, a saber: Bill Gates/Microsoft (US\$ 123,7 bilhões); Mark Zuckenberg/Facebook (US\$ 95,7 bilhões); Larry Page/Google (U\$ 90,9 bilhões); Sergey Brin/Google (U\$ 88,2 bilhões) e Larry Ellison/Oracle Corporation (US\$ 85,5 bilhões).

A implantação, desde os anos 90 do século passado, dos chamados Programas Sociedade da Informação em todo o mundo apontava para um uso cada vez mais intenso das tecnologias de informação e comunicação e, depois, da internet. Importante lembrar que a internet só começa a se consolidar a partir desse período, com a implantação dos chamados governos eletrônicos e a promessa de novas formas de participação para os cidadãos. Intensifica-se assim a disputa por mais transparência por parte dos governos, ao mesmo tempo em que se busca garantir maior privacidade para os cidadãos, cada vez mais ameaçados justamente por conta do poderio das chamadas plataformas da rede, a exemplo das big five: Google, Amazon, Facebook, Apple e Microsoft, conhecidas pelo acrônimo Gafam (SRNICEK, 2018). Acrescente-se a isso a existência de distintos agrupamentos em outros campos, que também têm sido significativos para a enorme concentração de poder nas mãos de poucos e poderosos. Estamos a nos referir à Natu (Netflix, Airbnb, Tesla e Uber) e, no mundo oriental, à BATX (Baidu, Alibaba, Tencent e Xiaomi) (SILVEIRA, 2017).

A educação é chamada, nesse contexto, a dar conta de preparar o cidadão para enfrentar todos esses desafios. Debate-se sobre as possibilidades de implantação de um sistema educacional que possibilite ao jovem viver o novo mundo do trabalho, agora automatizado, com a Inteligência Artificial (IA) e a Internet das Coisas (IoT) expandindo-se de forma acelerada. Assim, podemos considerar uma profunda crise da educação, a qual, diante do cenário brevemente delineado acima, precisa autoafirmar-se em seu papel constitucional, 
político e social de formação de cidadãos críticos, autônomos, participativos e comprometidos com as transformações sociais em prol do bem comum (RAVITCH, 2011).

Zygmunt Bauman (2015), imerso em um sentido de urgência, põe em xeque as formas com que aprendemos a lidar com os desafios da realidade. Como afirmou em entrevista ao Programa Milênio, da Globo News:

\begin{abstract}
As instituições de ação coletiva, nosso sistema político, sistema partidário, a forma de organizar a própria vida, as relações com as outras pessoas, todas essas formas aprendidas de sobrevivência no mundo não funcionam direito mais. Mas as novas formas que substituíram as antigas ainda estão engatinhando. (BAUMAN, 2015).
\end{abstract}

Acreditamos que a escola precisa se posicionar como um dos principais locus dessa construção, sob o risco de perder completamente seu sentido, a exemplo do que já acontece com os processos perversos de desqualificação e precarização da educação pública em diversos lugares do mundo, em especial no Brasil, com cortes brutais de verbas em todos os âmbitos.

Em todo o mundo, a presença das tecnologias digitais em rede tem crescido de forma exponencial, mas outros indicadores sociais ainda mantêm a sua forma desigual. Mesmo assim, esse crescimento tem estimulado a volta de um antigo debate sobre uma "sociedade sem escolas" (ILLICH, 1985) ou ainda sobre as propostas de uma educação doméstica (homeschooling), ${ }^{1}$ como estamos a ver no Brasil. Trabalhamos numa perspectiva oposta a essas duas propostas, por compreendermos que a educação, e a escola em particular, é um importante espaço de socialização das crianças e dos jovens, cujas possibilidades de convívio com o diferente não podem ser subtraídas. Entre os tantos pontos sensíveis que nos levam a não advogar em defesa da chamada educação domiciliar, resgatamos aqui o aspecto levantado por Luciana Temer, presidente do Instituto Liberta. Para ela, um argumento pouco utilizado é o da proteção da criança em relação à própria família, pois “[...] a escola é, muitas vezes, o único local onde a criança ou o adolescente encontra um adulto não ligado à sua família, para quem pode pedir socorro em uma situação de violência familiar” (TEMER, 2018).

Nesse sentido, nosso olhar está focado na escola. Mas esse olhar não pode se contaminar por uma visão dicotômica da intuição escolar, pois precisa compreender os grandes desafios que estão postos para todo o sistema de ensino. De um lado, uma crítica possível à escola é o fato de que o sistema mais amplo - as políticas públicas nacionais - não possibilita nada em seu interior que não seja a mera execução de tarefas pensadas e definidas alhures. De outro, a visão romântica de que, pela vontade pessoal do professor ou da professora, as coisas podem ali acontecer. Pensamos na busca por superar essa visão dicotômica, ou seja, sustentamos a ideia de que o sistema educacional terá que ser hackeado por dentro para fazer frente às questões que estão postas na contemporaneidade.

Buscamos, neste artigo, a partir das investigações em andamento em nossos grupos de pesquisa, ${ }^{2}$ refletir sobre a importância da escola e, mais especificamente, sobre as possibilidades de operar profundas 
transformações por dentro da própria escola. Para tal, a inspiração central de nossas pesquisas está nos movimentos e na cultura dos hackers. O título do artigo, inspirado no livro Abrir Instituciones desde dentro (Hacking Inside Black Box) (CORTÉS et al., [2019]), faz referência à urgência de encontrarmos formas de criar cavalos de troia que desestabilizem o sistema e tomem de assalto o ambiente escolar a partir de uma proposta de construção colaborativa, coletiva, emancipatória, democrática e criativa.

\section{Os hackers e a cultura}

Quando falamos em tecnologia e contemporaneidade, a cultura hacker é considerada exemplo de resistência digital. Partindo de diversos conceitos do pós-modernismo e do pós-estruturalismo, Charlie Gere (2002), em Digital Culture, apresenta uma visão geral dos últimos tempos históricos, teorias e grupos que inspiraram a resistência digital de hoje. Começando com movimentos dos anos 1970/1980, como fluxus e futurologistas, passando por Deleuze et al. (2000), Hardt e Negri (2000) e Donna Haraway (2002), Gere (2002) afirma que o punk foi um movimento de subcultura e resistência. A combinação punk de arte, música e prática de representação visual do tipo 'faça você mesmo' serviu como modelo para os designers gráficos nos anos 1980. Eles usaram pouco a tecnologia, no entanto eram fascinados por ela e, dessa forma, faziam um elogio ao fim da era industrial.

A música techno, com sua repetição e amostragem, de acordo com Charlie Gere (2002), também influência a cultura hacker, porque desafia a situação-padrão de um artista e do público. No techno, o disc jockey (DJ) e o público se fundem de tal maneira que um depende do outro, “[...] com o DJ e o público operando quase em uma espécie de relação de feedback cibernético"3 (GERE, 2002, p. 175).

Tendo sido influenciada por esses e por muitos outros movimentos, a cultura hacker, além de um exemplo de resistência, propõe formas alternativas de organizar o tempo e o trabalho, criando novos tipos de comunidade, diferentes dos modelos impostos pelo capitalismo (GERE, 2002). Aqui é importante trazer dois autores seminais no resgate e na busca por uma definição conceitual do que está sendo constituído a partir desses movimentos hackers. Trata-se de Steven Levy (2010) e de Pekka Himanen (HIMANEN; TORVALDS; CASTELLS, 2002), que buscaram definir o que passou a ser conhecido como a ética dos hackers.

Outra influência foi o cyberpunk, com sua mistura de tecnologia futurista e visão deteriorada do futuro. De Blade Runner a Matrix, exemplos dessa escrita de ficção científica sombria e experimental tornaram-se conhecidos pelo público em geral. Esses e muitos outros filmes tornaram o cyberpunk popular e chegaram à memória visual coletiva. Hoje em dia, com o seriado Black Mirror (Netflix), temos uma versão crítica não de um futuro longínquo, mas sim de um futuro próximo, o amanhã.

Nesse sentido, Michael Strangelove, em Empire of mind: Digital piracy and the anti-capitalist movement, propôs, no começo do século, a internet como espaço de livre expressão pessoal. Um espaço que estava se tornando uma nova forma de espaço público, que gerava novas formas de resistir ao controle. 
Strangelove (2005, p. 199) afirmou que a internet possui uma capacidade de “[...] expressão irrestrita, resistência e recursos de arquivamento (ela é um sistema de memória), que se combinaram para criar uma economia simbólica alternativa". ${ }^{4}$ Nossa pergunta é: será? Vimos, nessa última década, cada vez mais a intensificação do fechamento (jardins murados) via plataformas, que vem sendo enfrentado, em uma intensa disputa, pelos movimentos da cultura hacker na internet. Disputa essa em que a possibilidade de descentrabilidade da cultura digital está permanentemente sendo ameaçada pela concentração da rede em torno de poucas plataformas, pertencentes a grandes conglomerados, como os conhecidos e já mencionados Gafam, Natu e BATX. Esses movimentos concentracionistas estão baseados no poderio dos dados no mundo contemporâneo. A revista inglesa The Economist, de forte perspectiva econômica liberal, em sua edição de 6 de maio de 2017, não hesitou em afirmar que os dados são o novo petróleo. De acordo com a revista (DATA..., 2017), com base em dados do Wall Street Journal, em 2016, Amazon, Alphabet (Google) e Microsoft, juntas, acumularam perto de U\$ 32 bilhões em “[...] gastos com investimentos físicos e aluguel de bens de capital” (capital expenditure and capital leases), um aumento de $22 \%$ em relação ao ano anterior.

Os membros da Faang (Facebook, Amazon, Apple, Netflix e Google), sigla mais cara da história, alcançam níveis de capitalização tão altos que se assemelham ao Produto Interno Bruto (PIB) das grandes potências mundiais, senão vejamos: Facebook (US\$ 663,22 bilhões ou R \$3,47 trilhões), Amazon (US\$1,49 trilhão ou R \$ 7,79 trilhões), Apple (US\$ 1,61 trilhão ou R \$ 8,42 trilhões), Netflix (US\$210,62 bilhões ou R\$ 1,1 trilhão) e Alphabet (US\$ 1,03 trilhão ou R\$ 5,39 trilhões). Somando-se o valor de mercado (aprox. US\$ 5 trilhões), superam o PIB da Alemanha - a quarta maior economia do planeta -, que é de US\$3,96 trilhões (R\$ 20,7 trilhões) (VEGA, 2020).

Alexander R. Galloway (2004), em Protocol: How control exists after decentralization, questiona a vigilância na internet e demostra que o controle existe mesmo em redes descentralizadas. Como o protocolo é que executa as redes, é ele que permite uma conexão horizontal e regula o fluxo de informações. O protocolo se estabelece quando as duas partes estão de acordo com a realização da comunicação. No começo da internet, logo depois que o modem discava, surgia a imagem de um aperto de mãos, sinalizando que o protocolo tinha sido firmado e dois ou mais computadores estavam aptos a se comunicarem. Entretanto, é importante destacar que as formas de controle são inerentes e claras na internet; não à toa, diz Galloway, o protocolo que domina as conexões se chama Transmission Control Protocol/Internet Protocol (TCP/IP), e esse 'C' nada mais é do que Control (controle). A lógica de funcionamento das redes é constituída por um de dois níveis, sendo um deles o já mencionado TCP/IP, e o outro o Domain Name System (DNS). Ou seja, as redes dependem de ambos, do protocolo e do controle. Enquanto o TCP/IP permite o compartilhamento horizontal, a tecnologia distribuída e a conexão peer-to-peer, o DNS é um procedimento hierárquico e vertical. Ele regula os nomes de domínio como se fosse uma estrutura de árvore, com muitas ramificações, sendo os domínios de nível superior aqueles que dão sustentação à rede. São exemplos o .com (para comercial), .org (para organizações 
sem fins lucrativos) ou .br, .es, .uk (para localização no país, no exemplo, Brasil, Espanha e Reino Unido, respectivamente). Dessa forma, o DNS possibilita, caso um domínio de nível superior da rede seja removido pelo ente regulador, a remoção da $W e b$ de todos os conteúdos (sites), por exemplo, de organizações sem fins lucrativos (.org) ou mesmo de um país inteiro (Brasil, Espanha ou Reino Unido, nos exemplos citados).

Mas, para Galloway (2004), em um capítulo chamado Protocol futures, os hackers, potencialmente, podem ser os atores do protocolo, superando assim o controle. Tendo os hackers a possibilidade de hackear, diz Galloway, eles podem se constituir em atores do protocolo. Isso porque "Hacking é um índice das transformações protocológicas que ocorrem no mundo mais amplo da tecnocultura. Os hackers não preveem a morte (ou evasão ou ignorância) do protocolo, mas são o prenúncio de sua suposição" (GALLOWAY, 2004, p. 157). ${ }^{5} \mathrm{E}$ isso acontece por três razões principais, a saber:

- eles acreditam nas estruturas descentralizadas e horizontais;

- eles entendem de código para manipular e tornar a tecnologia mais adequada, melhor;

- eles trabalham com possibilidades, logo, para eles, se algo é possível, eles “podem” fazer.

Portanto, os hackers não tentam quebrar os protocolos, eles procuram lacunas ou vulnerabilidades em protocolos, para aproveitá-las e usá-las a seu favor.

Começamos assim a adentrar no campo da educação. A cultura hacker, como um campo em permanente disputa, vem se configurando como um movimento de resistência que paulatinamente ganha espaço em diversas áreas, a exemplo dos movimentos Software Livre, Acesso Aberto, Recursos Educacionais Abertos (REA), Hardware Livre, Parlamento e Governo Abertos, entre tantos outros. Seguindo esses movimentos, nós também direcionamos o foco de nossas pesquisas (e ativismo) para o trabalho com esses conceitos e práticas, articulados com a educação. Eles/nós - os hackers/educadores - atuam na sociedade com base em uma "[...] filosofia de compartilhamento, abertura, descentralização e do prazer de colocar as mãos sobre as máquinas a qualquer custo - desde que seja para aprimorá-las e também ao mundo" (LEVY, 2012, p. VII). É com base nesse espírito de manipular a tecnologia para uma sociedade melhor que trabalhamos nas escolas, com professores e estudantes. A ideia é criar possibilidades através da experiência e com isso vivenciar uma cultura do poder-fazer.

Mas ainda se faz necessário pensar um pouco mais sobre o que é essa cultura hacker que nos orienta. Armin Medosch (2005), no artigo Roots culture. Free software vibrations inna Babylon, compara a cultura hacker propagada por Richard Stallman (2002) com a cultura rastafári. Os rastas, rejeitando a linguagem do escravocrata, criaram sistemas alternativos de referência linguística baseados em dialetos jamaicanos e crioulos ingleses. Por exemplo, os rastas dizem overstanding em vez de understanding, porque o último termo implica submissão: 'entender estando abaixo' (é a palavra ‘entender' em inglês, mas usando o prefixo 'sobre' em vez de 'sob'). Medosh (2005) associa assim a atuação dos rastas aos projetos de artistas, engenheiros e 
desenvolvedores de software que usam software livre para criarem linguagens alternativas. Cita alguns exemplos: o grupo Mongrel, que está baseado no Reino Unido (https://monoskop.org/Mongrel); um desenvolvedor italiano chamado Jaromil; ${ }^{6}$ e o Pure Data (https://puredata.info/), uma linguagem de programação visual livre. Esses projetos e ferramentas artísticas abertos são inspiradores para quem busca fortalecer os conceitos de abertura e de liberdade, com clara inspiração para intensificar a propagação de valores atinentes aos movimentos do software livre e suas possíveis associações com uma educação que tenha a liberdade de criação como a principal motivação.

Outro pesquisador que aborda a influência hacker na cultura é Manuel Castells. Como elemento importante para sua formação, os hackers tornaram a internet um lugar aberto para a distribuição de informações e o trabalho colaborativo, numa construção que envolveu, em seu início, a ação de grupos hackers e mesmo de grandes empresas. Para Castells (2001, p. 77):

\begin{abstract}
A cultura da internet é uma cultura construída sobre a crença tecnocrática no progresso humano por meio da tecnologia, praticada por comunidades hackers que prosperam em um ambiente de criatividade tecnológica livre e aberta, baseado em redes virtuais dedicadas a reinventar a sociedade e materializadas por empresários capitalistas no trabalho da nova economia. ${ }^{7}$
\end{abstract}

Em seu início, o desenvolvimento da internet envolveu pesquisadores acadêmicos e jovens hackers, que, através de sistemas como o Bulletin Board System (BBS), compartilhavam informações e soluções para os desafios que emergiam da montagem da rede naqueles primórdios. Foi um rico período, que possibilitou, de um lado, uma rápida expansão da internet e o estabelecimento do que hoje denominamos de cultura da internet. Cultura essa que estava centrada na ideia de que todo o sistema que ali estava sendo desenvolvido revestia-se dos princípios da abertura e da liberdade. Tanto assim o foi que, hoje, uma das principais características desse desenvolvimento é o fato de que suas principais descobertas não foram patenteadas, e sim deixadas livres para uso pleno da humanidade. Para Castells (2001), tornava-se a internet um meio de estabelecer uma nova liberdade de expressão e comunicação horizontal, com potencial para se constituir em uma ferramenta para a ação coletiva e a organização social. Assim, a chamada cultura digital passou a ser compreendida como uma mistura de acadêmicos, hackers, comunidades e empreendedores. Ou seja, uma mistura de pesquisa, trabalho colaborativo, relações sociais e interesses capitalistas.

Hoje, sabemos que essas relações, fundamentais nos primórdios da internet, foram desequilibradas pelo crescimento vertiginoso dos empreendedores capitalistas, que passaram a dominar a rede, transformandoa em um jardim murado, com uma comoditização dos acessos e das navegações presa entre muros e uma subtração das liberdades em função da ação dos algoritmos que atuam no interior das plataformas, os quais são alimentados pelos dados pessoais de todos os usuários. Aquela utopia inicial de enormes possibilidades se transformou numa forma de vigilância e manipulação de informações (SRNICEK, 2018). 


\title{
Cultura livre
}

Nesses primeiros movimentos de desenvolvimento da internet, consideramos que a existência desses controles não impediu o surgimento do que ficou conhecido como cultura livre (LESSIG, 2001), sendo aquela internet um espaço aberto, no qual a informação poderia fluir irrestritamente. Com essa força, desde aquele momento, nascia uma articulação fundamental para o desenvolvimento da internet, o movimento em torno do software livre. Uma de suas principais lideranças, Richard Stallman, acredita que o software livre não é apenas uma maneira de criar softwares, mas essencialmente uma declaração política. O valor da liberdade está implícito em tudo que esteja relacionado ao movimento, uma vez que o que se estava criando era "um sistema baseado na cooperação voluntária e na descentralização"8 (STALLMAN, 2002, p. 131).

Esse espírito de compartilhamento, cooperação e liberdade se estende a diferentes áreas de nossas vidas. Estamos acostumados a isso e, segundo Stallman (2002, p. 164), aprendemos a compartilhar desde os tempos de criança:

\begin{abstract}
Quando eu ia para o jardim de infância, os professores tentavam nos ensinar essa atitude - o espírito de compartilhar - fazendo-nos praticar. Eles achavam que, se fizéssemos isso, aprenderíamos. Então, eles diziam: 'Se você levar doces para a escola, não poderá guardar tudo para você sozinho; você tem que compartilhar alguns com as outras crianças'. A sociedade foi criada para ensinar esse espírito de cooperação. E por que você tem que fazer isso? Porque as pessoas não são totalmente cooperativas. Essa é uma parte da natureza humana e existem outras partes da natureza humana. Existem muitas partes da natureza humana. Então, se você quer uma sociedade melhor, você tem que trabalhar para encorajar o espírito de compartilhamento. Nunca chegará a 100\%. Isso é compreensível. As pessoas também precisam cuidar de si mesmas. Mas, se o aumentarmos um pouco, estaremos melhor. ${ }^{9}$
\end{abstract}

Portanto, compreendemos que o movimento de software livre diz respeito a valores, dentre os quais o compartilhamento, a cooperação e a liberdade são os principais. O desenvolvimento de um software livre é essencialmente um ato colaborativo e de compartilhamento, e é graças a essa mobilização das comunidades em torno de determinados projetos que eles são desenvolvidos e aperfeiçoados.

Para ser livre, um software precisa obedecer a alguns princípios, que, essencialmente, são princípios de liberdade: a liberdade de criar, transformar, copiar, editar, distribuir e adaptar o software da melhor maneira possível. Esse é um resumo livre daquilo que ficou conhecido como as quatro liberdades do software livre, definidas quando da criação da Free Software Foundation. Um aspecto importante nesse debate tem a ver com a relação da palavra liberdade (freedom, em inglês) com a ideia de gratuidade, ou seja, como dizem os hackers: "Livres como na liberdade de expressão, não como na cerveja grátis".

Num ambiente de cooperação, Stallman critica a concorrência como uma forma de combate. No entanto, ele acredita em uma competição positiva, naquela que traz progresso, em que a melhor pessoa ganha a competição. Ele explica:

Se não queremos viver em uma selva, devemos mudar nossas atitudes. Devemos começar a enviar a mensagem de que um bom cidadão é aquele que coopera quando apropriado, e não aquele que é bemsucedido em tirar dos outros. Espero que o movimento do software livre contribua para isso: pelo menos 
em uma área, substituiremos a selva por um sistema mais eficiente, que estimule e opere com a cooperação voluntária. (STALLMAN, 2002, p. 132). ${ }^{10}$

Tomando as ideias de Stallman e indo mais adiante, Lawrence Lessig (2004) escreveu Free Culture, livro que discute liberdade e licenças. $\mathrm{O}$ autor defende a existência de um espaço para liberdade de expressão, compartilhamento e criação coletiva, o qual a internet poderia ocupar. Qualquer pessoa poderia, por exemplo, ter um servidor em casa e hospedar sites, uma vez que é razoavelmente fácil gerenciar um servidor, e alguns sistemas operacionais já vêm com esse recurso configurado. Lessig (2004) alerta ainda para o fato de que alguns provedores de internet - Internet Service Provider (ISP) - não permitem que seus clientes tenham seus próprios servidores, já que não desejam que os usuários usem a largura de banda para "transmitir". A internet, com seu grande potencial de viabilização da circulação de produções oriundas de diversas partes do país e do mundo, passa a ter um controle comercial que obsta o seu uso pleno. Esse fato, associado à grande concentração das plataformas digitais já referidas anteriormente, demanda ações políticas no sentido de fortalecer a possibilidade de uso pleno de todos esses recursos que foram criados e desenvolvidos pela humanidade. Nick Srnicek argumenta que esse enfrentamento poderia se dar através de plataformas cooperativas ou mesmo estatais, muito embora sustente que ambas são insuficientes para um bom desfecho da questão. Assim, avança no sentido de propor que se "[...] deveriam realizar esforços para criar plataformas públicas - plataformas de propriedade do povo e controladas por ele e, mais importante ainda, independentes do aparato de vigilância do Estado" (SRNICEK, 2018, p. 116).

Lessig, já em 2004, afirmava que nossa cultura é uma cultura de permissão em vez de uma cultura de liberdade. Devido às restrições e aos controles sobre quase todos os objetos culturais, as pessoas precisam de permissão para criar. Como se sabe, a criatividade depende da apropriação, da transformação, da (re)criação e de referências. Consequentemente, quando licenças e interesses comerciais diminuem essa liberdade de (re)criação, a cultura fica estagnada e a criatividade é retida. Sem controles, a cultura livre pode surgir.

\section{Uma ética e uma pedagogia hackers}

Pekka Himanen (HIMANEN; TORVALDS; CASTELLS, 2001), para melhor compreender o trabalho dos hackers, associou o trabalho deles ao modelo acadêmico de desenvolvimento da ciência, que é contrário ao sistema hierárquico de um monastério. De acordo com Himanen, originalmente, os cientistas também tinham um modelo aberto de pesquisa, pois eles costumeiramente liberam resultados dos seus estudos para que a comunidade possa estabelecer sua crítica e, a partir daí, essas descobertas possam ser melhoradas por todos. Ao longo dos últimos séculos, no entanto, o desenvolvimento da ciência trouxe o aprisionamento do conhecimento, muito estimulado pela lógica produtivista, que tomou conta da ciência mundial (BIANCHETTI; ZUIN; FERRAZ, 2018). Essa tendência vem sendo enfrentada por meio de um grande debate em torno da 
chamada ciência aberta/ciência cidadã, que preconiza a necessidade de pensar esse movimento, como afirma Sarita Albagli (ALBAGLI; MACIEL; ABDO, 2015, p. 10), “[...] a partir de duas grandes vertentes. Uma delas é a tensão hoje existente entre a socialização do conhecimento, da informação e da cultura, de um lado, e sua privatização, de outro". E a segunda vertente transcende o campo científico, trazendo para esse cenário em disputa o próprio significado de ciência aberta. Para a autora,

As abordagens da ciência aberta implicam superar a perspectiva de pensar a ciência a partir da sua produtividade intrínseca. Implicam o abalo de hierarquias, de fontes estabelecidas de autoridade e reputação, colocando foco nas relações entre ciência e poder, e, mais amplamente entre saber e poder. (ALBAGLI; MACIEL; ABDO, 2015, p. 10).

Voltando então aos hackers, o que podemos constatar é que esse exercício de constituição de comunidades e de desenvolvimento aberto de softwares tem gerado como resultado o amplo e rápido desenvolvimento de soluções no campo da Tecnologia da Informação (TI), que são marcantes no mundo contemporâneo. Assim, podemos dizer que o GNU/Linux é um exemplo real da implementação da chamada ética hacker. Pekka Himanen (2001, p. 139-141), ao analisar a ética dos hackers, identificou o que ele chama de sete valores inerentes a essa ética, com a ressalva de que não se trata de valores absolutos. Sua construção busca identificar, a partir de sua experiência e vivência, a maneira como os hackers atuam na sociedade. Esses valores são: paixão, liberdade, valor social, abertura, atividade, cuidado e criatividade. A paixão corresponde ao entusiasmo e à alegria de fazer o trabalho, tendo como base a ideia de liberdade como um estilo de vida, bem como à liberdade de poder trabalhar quando melhor convier. O trabalho social é referido como o trabalho feito 'por' uma comunidade e 'para' uma comunidade, ganhando, por isso, reconhecimento. A abertura é a concepção de que o trabalho está aberto para ser mudado, melhorado e copiado. Atividade é o conceito de fazer algo com o que você acredita, de colocar em prática seus princípios. O cuidado está relacionado ao respeito; quando todos podem participar de uma comunidade, é importante se preocupar com o outro, a fim de cultivar um ambiente harmonioso. Por último, a criatividade é o valor de criar algo novo, surpreendente ou autêntico. É a inovação de recursos para o software ficar mais fácil, mais prático e completo.

Karina Menezes (2018), em seu trabalho Pirâmide da Pedagogia Hacker: de sonhos coletivos a engajamentos reais, apresenta-nos algumas outras considerações sobre essa ética, as quais ela denomina de “preceitos". Para a autora, com base no que analisou ao longo de sua tese:

\footnotetext{
1) a cultura hacker é uma cultura de doação, nesse caso, de doação de ideias, de tempo. 2) É também uma cultura façocrata, é o reconhecimento de quem coloca a mão na massa. Não se delega trabalho a outrem. 3) É uma cultura colaborativa, na qual qualquer interessado pode contribuir, mesmo que não tenha muito conhecimento na área, e portanto, 4) é uma cultura de compartilhamento, pois aqueles que sabem um pouco mais trocam conhecimento com aqueles que sabem menos acerca de certo assunto. (MENEZES, 2018, p. 113).
}

A partir da observação sobre a pedagogia emergente em hackerspaces - espaços tecnológicos comunitários -, Menezes (2018) aponta a existência de uma "pedagogia hacker", cuja força motriz é um 
engajamento multifacetado, pois trata de inclinações e motivações específicas, fortalecidas pela convivência. As faces desse engajamento se expressam por meio de quatro dimensões: i) a técnica, cuja motivação é desenvolver conhecimentos e habilidades técnicas; ii) a afetiva, relacionada ao fato de estar em um local do qual se gosta ou com pessoas com as quais se tem afinidade; iii) a ideária, que diz respeito a fazer algo porque acredita; e iv) a ativista, através da qual se coloca a mão na massa, modifica-se algo ou alguém pelo agir. A entrada e a permanência de pessoas em hackerspaces se dão à medida que esses engajamentos são construídos pelos seus integrantes, e, para que isso seja possível, é preciso que o espaço seja acolhedor e diverso, como deveria ser a escola.

Aragão, Bompet e Menezes (2020), em artigo intitulado Juventude ciberativista e educação: reflexões sobre um jeito hacker de ser, afirmam que a organização escolar, que se vê sob amarras históricas e limitações legais no que diz respeito à sua organização e atuação, tende a reduzir seu potencial de abertura para novas práticas, além de enfrentar restrições de ordem infraestrutural e a ausência de formações para professores focadas na apropriação das tecnologias, mas para além da perspectiva reducionista do uso como ferramenta para dinamizar as aulas. A apatia e a evasão de significativa parte da juventude dos contextos de educação formal se devem também a esse descompasso entre o que os jovens encontram dentro das escolas e aquilo de que desfrutam no âmbito das redes sociais digitais. Para esse enfrentamento, propomos hackear a educação por dentro.

\section{Hackear a educação por dentro}

Como já afirmamos, estamos trabalhando em nossas pesquisas inspirados no projeto do Laboratório de Aragón Gobierno Abierto (LAAAB) (CORTÉS, et al., [2019]), que se propõe a “Abrir instituciones desde dentro" [Hacking Inside Black Book]. Esses projetos, segundo os autores,

[...] compartilham um código fonte: eles são projetados para atuar como dispositivos troianos, abrindo o sistema a partir de dentro, gerando passagens laterais, zonas francas de confluência, remixando e trocando experiências, flexibilizando e ressignificando as relações entre organizações e os cidadãos. (CORTÉS, et al., [2019], p. 93-96). ${ }^{11}$

Na proposta do governo aragonês, como uma política de governo, as ideias expostas são a lealdade ao sistema e sua perspectiva "reformista" (CORTÉS, et al., [2019]), o que difere do que neste artigo estamos a propor, pois, ao fim e ao cabo, o que buscamos é provocar modificações no todo a partir de dentro, sem que haja uma imobilização enquanto não se tem uma transformação macroestrutural da sociedade. Mas estamos parcialmente de acordo com eles, porque também queremos que os “[...] elementos intangibles, como las conversaciones, conexiones, proyectos conjuntos y redes de complicidades que se crean" (CORTÉS, et al., [2019], p. 133-134), sejam os mais importantes e o motor das ações no interior das escolas. 
Hackear a educação por dentro, portanto, significa trabalhar com os valores e as práticas da chamada ética hacker dentro da escola, em conjunto com professores, alunos e comunidade, bem como construir conhecimento e projetos colaborativos como parte da sabedoria e do aprendizado.

$\mathrm{Na}$ tese intitulada Educação hacker e empoderamento: das comunidades hackers até a escola, defendida em outubro de 2020, na Universidade Autônoma de Barcelona, Alexandre Aguado apresenta, como fruto de suas análises, seis dimensões (inquietação, ação-diversão, coletivo, sociedade-comunidade, compartilhamento e humanístico-tecnológica), que, juntas, apoiam a compreensão da educação hacker. Pensamos ser necessária a longa citação do autor para melhor explicitar essas dimensões:

\begin{abstract}
A dimensão da inquietação representa o que move a ação e aprendizagem de hackers, a curiosidade e a postura crítica que colocam os hackers em movimento. A dimensão ação-diversão, que se refere ao método com que os hackers buscam sanar suas inquietações, com uma postura ativa, baseada na experimentação, na pesquisa, no remix e na ação criativa. Tal ação não é enfadonha nem fruto da obrigação. É atuar em algo que se quer fazer, que é divertido, que seja uma ação-diversão. A dimensão do coletivo traz consigo a afirmação de que a educação hacker ocorre de forma coletiva, e não individualista. É um grupo marcado pela ajuda mútua, pelo cuidado e pelas relações horizontais. A dimensão sociedade-comunidade refere-se ao fato de que este grupo não se constitui isoladamente da sociedade, mas, em alguns casos, problematiza dinâmicas sociais, atua de forma ativista e forma redes com outras pessoas e coletivos. A dimensão de compartilhamento representa o espírito de abertura do hacker, no qual conhecimentos e recursos são compartilhados abertamente dentro e fora da comunidade, valorizando e criando os bens comuns. A criação desses bens também é uma forma de as comunidades interagirem com a sociedade. Finalmente, a dimensão humanístico-tecnológica representa a inseparabilidade entre esses dois elementos, que, para os hackers, são essenciais na forma de fazer educação. As maneiras pelas quais as sociedades se apropriam das tecnologias podem determinar suas direções e, quando nesses processos se esquece de que o ser humano deve vir sempre antes de qualquer artefato tecnológico, os efeitos podem ser trágicos. (AGUADO, 2020, p. 465, tradução nossa).
\end{abstract}

Os desafios não são pequenos, pois, como já mencionamos, passamos de uma fase apologética da internet e das redes digitais para um momento de estranha configuração. Para Morozov (2018, p. 49), temos que ter muita cautela quando abordamos os benefícios das tecnologias para a sociedade, para não cairmos no “[...] conto de fadas do empoderamento do usuário, proposto pelo Vale do Silício". ${ }^{12}$ Para o autor, questões históricas da humanidade, a exemplo da democracia, da discrepância econômica e dos preconceitos sociais, não serão resolvidas pelo avanço das tecnologias digitais. Esses são temas muito mais profundos, que independem da ação individual do ser humano, pois estão relacionados a questões educacionais, de segurança pública, de preconceito social, aliadas a uma política governamental de retrocessos sociais, dentre outros fatores.

As expectativas em torno de um futuro promissor potencializado pelas redes mobilizou não apenas acadêmicos mas também artistas, como, por exemplo, Gilberto Gil, que compôs, em 1996, uma música denominada Pela Internet, uma das primeiras músicas transmitidas ao vivo pela rede no Brasil. De lá para cá, estamos a ver a necessidade de intensificar a disputa em torno dos conceitos de rede, de internet, de proteção de dados pessoais, dentre outros aspectos que têm nos mantido atentos e demandando da educação um outro e mais profundo olhar sobre a presença das tecnologias digitais na escola. O próprio Gilberto Gil fez uma 
releitura de sua música e, cerca de 20 anos depois, lançou Pela Internet 2 (2018), em que adota uma postura menos encantada e mais crítica:

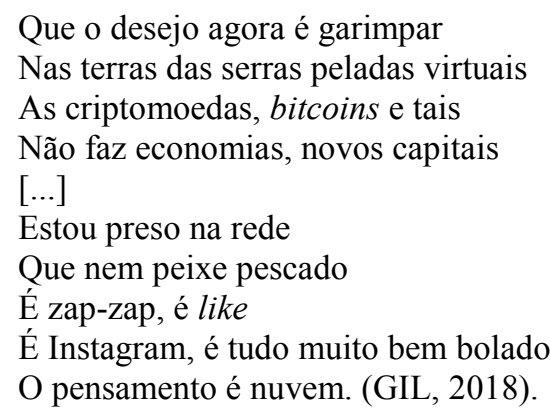

A luta pela libertação das plataformas e da internet, pelo fim do controle sobre os dados pessoais e pela retomada da dimensão artesã do trabalho de professores e alunos nos leva a propor uma educação que compreenda e considere a perspectiva plural da sociedade. Um sistema educacional que valorize a escola em sua singularidade, que trabalhe para a emancipação, a autoria e a produção colaborativa, numa intensa relação com outros saberes da sociedade. Assim, alunos e professores passam a (re)assumir o papel autoral de fazedores do seu próprio tempo, instituindo dessa forma um círculo virtuoso de produção de culturas e conhecimentos.

Notas

${ }^{1}$ O tema é assunto de projetos de lei (PL) como o PL 2.401/2019, que foi encaminhado para votação em abril de 2019. Paralelamente, o presidente da República assinou uma Medida Provisória instituindo a educação domiciliar, mas o Supremo Tribunal Federal (STF) considerou o tema inconstitucional. Existe no Brasil uma organização para tratar do tema, a Associação Nacional de Educação Domiciliar (Aned) (https://www.aned.org.br).

${ }^{2}$ Aqui nos referimos especialmente à pesquisa Conexão Escola-Mundo: espaços inovadores para formação cidadã (edital CNPq CHSSA 2016, processo número 440065/2017-8).

${ }^{3}$ Tradução livre de "with the DJ and the audience operating almost in a kind of cybernetic feedback relation".

${ }^{4}$ Tradução livre de "Unconstrained expression, resistance, and the Internet's archival capabilities (it is a memory system) have combined to create an alternative symbolic economy".

${ }^{5}$ Tradução livre de "Hacking is an index of protocological transformations taking place in the broader world of techno-culture. Hackers do not forecast the death (or avoidance or ignorance) of protocol, but are instead the very harbinger of its assumption".

${ }^{6}$ Ele criou um software chamado Dyne:bolic para produção de multimídia e transmissão. Jaromil o chama de software Rasta.

${ }^{7}$ Tradução livre de "La cultura de Internet es una cultura construida sobre la creencia tecnocrática en el progreso humano a través de la tecnología, practicada por comunidades de hackers que prosperan en un entorno de creatividad tecnológica libre y abierto, asentada en redes virtuales dedicadas a reinventar la sociedad y materializada por emprendedores capitalistas en el quehacer de la nueva economía".

${ }^{8}$ Tradução livre de "a system based on voluntary cooperation and on decentralization".

${ }^{9}$ Tradução livre de "When I was going to kindergarten, the teachers were trying to teach us this attitude - the spirit of sharing - by having us do it. They figured if we did it, we'd learn. So they said, "If you bring candy to school, you can't keep it all for yourself; you have to share some with the other kids." The society was set up to teach this spirit of cooperation. And why do you have to do that? Because people are not totally cooperative. That's one part of human nature, and there are other parts of human nature. There are lots of parts of human nature. So, if you want a better society, you've got to work to encourage the spirit of sharing. It'll never get to be $100 \%$. That's understandable. People have to take care of themselves too. But if we make it somewhat bigger, we 're all better off." 


\begin{abstract}
${ }^{10}$ Tradução livre de "We must start sending the message that a good citizen is one who cooperates when appropriate, not one who is successful at taking from others. I hope that the free software movement will contribute to this: at least in one area, we will replace the jungle with a more efficient system that encourages and runs on voluntary cooperation".

${ }^{11}$ Tradução livre de "Los proyectos en los que trabajamos comparten un código fuente: están pensados para actuar como dispositivos troyanos, abriendo el sistema desde dentro, generando pasadizos laterales, zonas francas de confluencia, experiencias de remezcla e intercambio, donde flexibilizar y resignificar las relaciones entre las organizaciones y los ciudadanos. Proyectos troyanos que operan en todo caso desde la más absoluta lealtad al sistema."

${ }^{12}$ Localizado na Califórnia (EUA), o Vale do Silício é considerado o maior polo de tecnologia e inovação do mundo. No local, há grande concentração de empresas de grande lucratividade, como Facebook, Google e Uber. A palavra silício faz uma alusão ao elemento químico de mesmo nome, amplamente utilizado na fabricação de componentes eletrônicos de computadores.
\end{abstract}

\title{
Referências
}

AGAMBEN, Giorgio. Stato de Eccezione. [S. l.]: Bollati Boringhieri, 2003.

AGUADO, Alexandre. Educación Hacker y Empoderamiento de las comunidades hacker hasta la escuela. 2020.560 f. Tese (Doutorado em Ciência e Educação) - Facultat Ciències de I'EDucació, Universitat Autònoma de Barcelona, Barcelona, 2020.

ALBAGLI, Sarita; MACIEL, Maria Lucia; ABDO, Alexandre Hannud (org.). Ciência Aberta, questões abertas. Brasília: IBICT; Rio de Janeiro: Unirio, 2015. Disponível em: https://bit.ly/3pRVIwm. Acesso em: 12 dez. 2019.

ARAGÃO, Carla; BOMPET, Pietro Matheus Fontoura; MENEZES, Karina. Moreira. Juventude ciberativista e educação: reflexões sobre um jeito hacker de ser. Ámbitos: Revista Internacional de Comunicación, Sevilla, n. 50, p. 116-127, 2020. DOI: https://doi.org/10.12795/Ambitos.2020.i50.08. Disponível em: https://bit.ly/3gjBTdU. Acesso em: 23 fev. 2021.

BAUMAN, Zygmunt. A fluidez do "mundo líquido". Milênio. GloboNews, Rio de Janeiro, 2015.1 vídeo (aprox. 5 min). son., col. Disponível em: https://glo.bo/3gtjGtm. Acesso em: 17 out. 2019.

BERNERS-LEE, Tim. I invented the web. Here are three things we need to change to save it. The Guardian, [S. l.], 12 mar. 2017. Disponível em: https://bit.ly/2TrD2qQ. Acesso em: 11 nov. 2019.

BIANCHETTI, Lucídio; ZUIN, Antonio A. S.; FERRAZ, Obdália. Publique, apareça ou pereça: produtivismo acadêmico, "pesquisa administrada" e plágios nos tempos da cultural digital. Salvador: Edufba, 2018.

BILIONÁRIOS ficam mais ricos, enquanto mundo vê saltar a desigualdade. O Globo, Rio de Janeiro, 8 out. 2020.

CASTELLS, Manuel. La galaxia internet. Tradução: Raul Quintana. Barcelona: Areté, 2001.

CASTELLS, Manuel. Redes de indignação e esperança: movimentos sociais na era da internet. Tradução: Carlos Alberto Medeiros: Rio de Janeiro: Zahar, 2013.

CORTÉS, Raúl Oliván et al. (org.). Abrir instituciones desde dentro [Hacking inside]. Aragón: LAAAB, [2019]. Disponível em: https://bit.ly/2VnInAq. Acesso em: 23 fev. 2020.

DATA is giving rise to a new economy. How is it shaping up? The Economist, [S. l.], 6 maio 2017. Disponível em: https://econ.st/2ToLPtJ. Acesso em: 18 jun. 2019.

DELEUZE, Gilles et al. Mil Platôs: capitalismo e esquizofrenia. Rio de Janeiro: Editora 34, 2000. v. 1.

FORBES. Real-time billionaries. Banco de dados sobre milionário. Forbes, [S. l.], 2021. Disponível em: https://bit.ly/2SngU0X. Acesso em: 19 fev. 2021.

GALlOWAY, Alexander R. Protocol: how control exists after decentralization. Cambridge: MIT Press, 2004.

GERE, Charlie. Digital Culture. London: Reaktion Books, 2002.

GOMES, Wilson. A democracia no mundo digital: história, problemas e temas. São Paulo: SESC, 2018.

HARAWAY, Donna. A Cyborg Manifesto. In: SPILLER, Neil (org.). Cyber reader: critical writings for the digital era. 
HARDT, Michael; NEGRI, Antonio. Empire. Cambridge: Harvard University Press, 2000.

HIMANEN, Pekka; TORVALDS, Linus; CASTELLS, Manuel. The hacker ethic and the Spirit of the Information Age. New York: Random House Trade, 2002.

ILLICH, Ivan. Sociedade sem escolas. Tradução: Lúcia Mathilde Endlich Orth. 7. ed. Petrópolis: Vozes, 1985.

LESSIG, Lawrence. The future of ideas: the fate of the commons in a connected world. 1. ed. New York: Random House, 2001.

LESSIG, Lawrence Free Culture: How Big Media uses technology and the law to lock down culture and control creativity. New York: Penguin Press, 2004.

LEVY, Steven. Hackers: heroes of the computer revolution. Newton: O’Reilly Media, 2010.

LEVY, Steven. Os heróis da revolução: como Steve Jobs, Steve Wosniak, Bill Gates, Mark Zuckenberg e outros mudaram para sempre nossas vidas. São Paulo: Évora, 2012.

MALINI, Fábio; ANTOUN, Henrique. @ internet e \# rua: ciberativismo e mobilizações nas redes sociais. Porto Alegre: Sulina, 2013.

MENEZES, Karina Moreira. P2H: Pirâmide da Pedagogia hacker = [vivências do (in)possível]. 2018. 180f. Tese (Doutorado em Educação) - Faculdade de Educação, Universidade Federal da Bahia, Salvador, 2018. Disponível em: https://bit.ly/3gKZ547. Acesso em: 23 fev. 2021.

MEDOSCH, Armin. Roots Culture: Free Software vibrations "inna Babylon". In: CENTRE FOR THE STUDY OF DEVELOPING SOCIETIES (org.). Sarai Reader 05: Bare Acts. Delhi: Sarai Programme, 2005. p. 222-240. Disponível em: https://bit.ly/3gAVWDU. Acesso em: 20 jun. 2019.

MESQUITA, Ligia. Denúncias de discurso de ódio online dispararam no $2^{\circ}$ turno das eleições, diz ONG. BBC News Brasil, [S. l.], 9 nov. 2018. Disponível em: https://bbc.in/3iBT6AS. Acesso em: 1 jan. 2019.

MOROZOV, Evgeny. Big tech: a ascensão dos dados e a morte da política. Tradução: Claudio Marcondes. 1. ed. São Paulo, Editora Ubu, 2018.

PAMPLONA, Nicola. 10\% mais rico ficam com 43\% da renda nacional, diz IBGE. Folha de São Paulo, São Paulo, 6 maio 2020. Disponível em: https://bit.ly/3wkprAd. Acesso em: 19 fev. 2021.

RAVITCH, Daiane. Vida e Morte do grande sistema escolar americano: como os testes padronizados e o modelo de mercado ameaçam a educação. Porto Alegre: Sulina, 2011.

SAFATLE, Vladimir. Só mais um esforço. São Paulo: Três Estrelas, 2018.

SILVEIRA, Sergio Amadeu. Tudo sobre tod@s: redes digitais, privacidade e venda de dados pessoais. São Paulo: SESC, 2017.

SRNICEK, Nick. Capitalismo de plataformas. Buenos Aires: Caja Negra, 2018.

STALLMAN, Richard. Free software, free society: Selected essays of Richard Stallman. Boston: GNU Press, 2002.

STRANGELOVE, Michael. The Empire of Mind: Digital piracy and the Anti-capitalist Movement. Toronto: University of Toronto Press, 2005.

TEMER, Luciana. A decisão do STF de considerar ilegal a educação domiciliar foi correta? SIM. Dos riscos que ninguém falou. Folha de São Paulo, 22 set. 2018. Disponível em: https://bit.ly/3glcP6E. Acesso em: 20 set. 2020.

VEGA, Miguel Ángel García. Faang: a sigla mais cara da história. El País, Madri, 25 jul. 2020. Disponível em: https://bit.ly/3gtMmmb. Acesso 20 fev. 2021 